\title{
Immaturity-Dependent Free Radical Activity in Premature Infants
}

\author{
EEVA VARSILA, OLLI PITKÄNEN, MIKKO HALLMAN, AND STURE ANDERSSON
}

Children's Hospital, University of Helsinki, Helsinki, Finland (E.V., S.A.]; Neonatology

Research Division, Hospital for Sick Children, Toronto, Ontario, Canada 1O.P.|; University of

California, Irvine, California 92717 [M.H.]; and Departments I and II of Obstetrics and

Gynecology, University of Helsinki, Helsinki, Finland [S.A.]

\section{ABSTRACT}

To examine the role of immaturity in the free radicalmediated rate of lipid peroxidation in premature infants, we studied 27 infants [gestational age, 27.1 (SD 2.4) wk; birth weight, 970 (SD 330) g]. Ethane and pentane were quantitated in expired air during the first $18 \mathrm{~d}$ of life. During the first 2 postnatal $d$ ethane [24.1 (SEM 7.8) pmol $\times \mathrm{kg}^{-1} \times$ $\min ^{-1}$ ] and pentane [24.2 (SEM 4.1) pmol $\left.\times \mathrm{kg}^{-1} \times \mathrm{min}^{-1}\right]$ were stable but increased during d 5 to maxima of 79.1 (15.8) $\mathrm{pmol} \times \mathrm{kg}^{-1} \times \mathrm{min}^{-1}$ and 62.1 (8.1) pmol $\times \mathrm{kg}^{-1} \times$ $\min ^{-1}$, respectively. Maximum ethane and pentane correlated with gestational age $(r=-0.42, p=0.03$ and $r=$ $-0.52, p=0.005$, respectively) and birth weight $(r=$ $-0.38, p=0.05$ and $r=-0.59, p=0.001$, respectively). Infants with high maximum expired ethane and pentane (exceeding $40 \mathrm{pmol} \times \mathrm{kg}^{-1} \times \mathrm{min}^{-1}$ ) had higher odds of dying or having bronchopulmonary dysplasia than those with low ethane and pentane (odds ratio, 6.5; 95\% confi-

The newborn at term is better protected against the effects of free oxygen radicals than are prematurely born and adult individuals $(1,2)$. The reasons for such resistance are possibly the high activity of antioxidant enzymes and the capacity for induction of activity of these enzymes in response to oxidative challenge $(1,3,4)$. Additionally, the concentrations of antioxidants are low in the premature infant $(2,5)$. Moreover, the prematurely born infant is frequently exposed to conditions associated with increased generation of free oxygen radicals, such as reperfusion and hyperoxia $(6,7)$. It has been proposed that free oxygen radicals participate in the pathogenesis of BPD and ROP (8-10).

In excess, free oxygen radicals may damage biologic macromolecules (11). Especially vulnerable are polyunsaturated fatty acids, in which free oxygen radicals may

Received June 24, 1993; accepted February 1, 1994.

Correspondence: Eeva Varsila, M.D., Children's Hospital, Stenbäckinkatu 11, 00290 Helsinki, Finland.

Supported by the AGA AB Medical Research Fund, the Foundation for Pediatric Research, the Paulo Foundation, and the Finnish Academy. dence interval, 1.1 to $38.5 ; p<0.05$ for ethane and odds ratio, 5.6; $95 \%$ confidence interval, 1.1 to $29.3 ; p<0.05$ for pentane). We conclude that degree of prematurity is the single most important factor explaining free radicalmediated lipid peroxidation in premature infants. A therapeutic intervention to limit the effects of free radicals should be started during the 1 st postnatal $d$ in premature infants to be effective. (Pediatr Res 36: 55-59, 1994)
Abbreviations
BPD, bronchopulmonary dysplasia
IVH, intraventricular hemorrhage
OR, odds ratio
PDA, patent ductus arteriosus
ROP, retinopathy of prematurity
CI, confidence interval

induce lipid peroxidation that causes disturbance of membrane function and eventual cell death (12).

Lipid peroxidation generates volatile products, e.g. ethane and pentane, the concentrations of which in expired air serve as indicators of the free radical activity $(13,14)$. The aim of the present investigation was to analyze the factors associated with free radical activity by quantifying ethane and pentane in expired air.

\section{PATIENTS AND METHODS}

Patients. A total of 27 infants were studied at the Children's Hospital of the Helsinki University Central Hospital (Table 1). All infants were born before 32 wk of gestation (range, 23 to $32 \mathrm{wk}$ ) and were admitted to the neonatal intensive care unit. Relative birth weight was estimated by standard Finnish intrauterine growth diagrams (birth weight of the infant minus mean weight at the infant's age divided by SD of birth weight at this gestational age).

The requirement of the fraction of inspiratory oxygen was adjusted to maintain arterial oxygen tension between 
Table 1. Patient characteristics

\begin{tabular}{lc}
\hline Number & 27 \\
Gestational age (wk) & $27.1 \pm 2.4^{*}$ \\
Birth weight (g) & $973 \pm 330^{*}$ \\
Relative birth weight & $-0.5 \pm 1.4^{*}$ \\
Delivery (cesarean & $14 / 13$ \\
section/vaginal) & \\
Preeclampsia & 4 \\
Chorioamnionitis & 8 \\
Apgar score-1 min & $5 \pm 2^{*}$ \\
Apgar score-5 min & $7 \pm 2^{*}$ \\
Apgar score-10 min & $8 \pm 1^{*}$ \\
Respiratory distress syndrome & 24 \\
PDA & 13 \\
IVH & \\
Grade I & 5 \\
Grades II-IV & 7 \\
BPD & 9 \\
ROP & 2 \\
Death & 7 \\
\hline * Mean \pm SD &
\end{tabular}

50 and $80 \mathrm{~mm} \mathrm{Hg}(6.7$ and $10.7 \mathrm{kPa})$. All infants had intubation and ventilation because they failed to establish sufficient spontaneous ventilation at birth. Twenty-four patients had respiratory distress syndrome. Two of these patients received exogenous surfactant (human surfactant isolated from amniotic fluid), one at the age of $2 \mathrm{~h}$ and one at the age of $5 \mathrm{~h}$. Symptomatic PDA developed in 13 infants. The diagnosis of PDA was determined by echocardiography. Four doses of i.v. indomethacin $(0.1$ $\mathrm{mg} \times \mathrm{kg}^{-1}$ ) at 8 - to 12 -h intervals was administered to these patients. All infants received i.v. glucose, ampicillin $\left(200 \mathrm{mg} \times \mathrm{kg}^{-1} \times \mathrm{d}^{-1}\right)$, and netilmycin $\left(6 \mathrm{mg} \times \mathrm{kg}^{-1}\right.$ $\left.\times \mathrm{d}^{-1}\right)$ during the first $7 \mathrm{~d}$. Seven of the patients had leukopenia, thrombocytopenia, and elevated $C$ reactive protein indicative of infection, but the results of their blood cultures were negative. All the infants received i.v. fluconazole $\left(6 \mathrm{mg} \times \mathrm{kg}^{-1} \times \mathrm{d}^{-1}\right)$ as prophylaxis against fungal infections. I.v. lipid infusion (Intralipid, Kabi Ltd.) was started on $d 3$ to $d 5$ of life unless oral feeding had been established. Vitamins A $(100 \mu \mathrm{g}), \mathrm{D}(1.5 \mu \mathrm{g}), \mathrm{C}$ $(100 \mathrm{mg})$, and $\mathrm{E}(1 \mathrm{mg})$ were started i.v. at the beginning of lipid infusion or given perorally to patients receiving more than $10 \mathrm{~mL} \times \mathrm{kg}^{-1} \times \mathrm{d}^{-1}$ human milk. IVH was diagnosed by cranial ultrasonography, and the findings were classified according to Papile et al. (15). BPD was diagnosed according to the criteria of Bancalari and Gerhardt (16) when the infant was $28 \mathrm{~d}$ old. ROP was diagnosed and graded as described (17).

The study protocol was approved by the Ethics Committee of the Children's Hospital, and informed consent was obtained from the parents.

Collection and quantitation of alkanes. Single samples of expired air were collected daily for $10 \mathrm{~d}$ and then at 2- to $3-\mathrm{d}$ intervals until the infants were $18 \mathrm{~d}$ of age. The patients breathed hydrocarbon-free air oxygen for $5 \mathrm{~min}$, after which expired air was sampled during $2 \mathrm{~min}$. Expired air was sampled through the intubation tube; if extubated, it was sampled through a gas-tight face mask (infant mask, Laerdal, Stavanger, Norway). With the face mask, the infant was breathing against a positive pressure at a constant flow of $2-4 \mathrm{~L} \times \mathrm{min}^{-1}$. Ethane and pentane were analyzed by gas chromatography with a capillary column, with 2-pentene as an internal standard (14). Expired gas samples were additionally analyzed for carbon dioxide (Capnometer model CD 101, Datex Ltd.).

Statistical analysis. The data are expressed as mean \pm SEM unless otherwise indicated. Logarithmic transformation of ethane and pentane values was performed to normalize the distribution. The unpaired two-sided $t$ test was used to detect differences between the two groups. The postnatal profile of alkane excretion was examined with analysis of variance. Associations between prenatal and postnatal factors and expired gases were analyzed by multiple regression test. Association of high pentane excretion with BPD, neonatal death rate, IVH, and PDA is expressed with OR (odds of the specific complication to noncomplication), with $95 \% \mathrm{CI}$.

\section{RESULTS}

Between the 1st and 18th d of life, 27 premature infants were studied. All infants required ventilatory support immediately after birth. The collection of the first expired gas sample took place within the first $24 \mathrm{~h}$. The expiration of ethane and pentane during the first $2 \mathrm{~d}$ was $24.1 \pm 7.8$ pmol $\times \mathrm{kg}^{-1} \times \min ^{-1}$ and $24.2 \pm 4.1 \mathrm{pmol} \times \mathrm{kg}^{-1} \times$ $\min ^{-1}$, respectively. Both ethane and pentane increased to a peak, with ethane at $79.1 \pm 15.8 \mathrm{pmol} \times \mathrm{kg}^{-1} \times$ $\min ^{-1}$ and pentane at $62.1 \pm 8.1 \mathrm{pmol} \times \mathrm{kg}^{-1} \times \min ^{-1}$ on d 5 . Thereafter, between $\mathrm{d} 5$ and 8 , both ethane and pentane decreased $(p<0.05)$ (Fig. 1).

During the study period of up to $18 \mathrm{~d}$, eight infants were fed enterally, starting with $10 \mathrm{~mL} / \mathrm{d}$ of human milk. For 22 of the infants, i.v. amino acids and lipids were started at a mean age of $4.8 \pm 1.1 \mathrm{~d}\left(5-10 \mathrm{~mL} \times \mathrm{kg}^{-1}\right.$ amino acid infusion and $5 \mathrm{~mL}$ i.v. lipid infusion each). Infusion of lipids was stopped at least $3 \mathrm{~h}$ before collection of gas samples.

Gestational age at birth and birth weight showed an inverse correlation with maximal alkane expiration. The peak of ethane expiration significantly correlated with gestational age $(r=-0.42, p=0.03)$ and birth weight $(r$ $=-0.38, p=0.05$ ). Corresponding correlations for the pentane peak were to gestational age $(r=-0.52, p<$ $0.005)$ and birth weight $(r=-0.59, p<0.001)$. The following parameters had no detectable association with the peak alkane excretion: mean oxygen requirement before the peak for alkanes (ethane: $r=0.22, p=0.30$; pentane: $r=0.32, p=0.12$ ), daily mean airway pressures or arterial oxygen tensions before the peak, intubation time, or start of enteral or parenteral nutrition.

Multiple regression analyses were performed to distinguish which factors were associated with the peaks of ethane and pentane excretions (Table 2). The ethane and pentane peaks increased significantly with low gestational age regardless of the level of oxygen supplemen- 

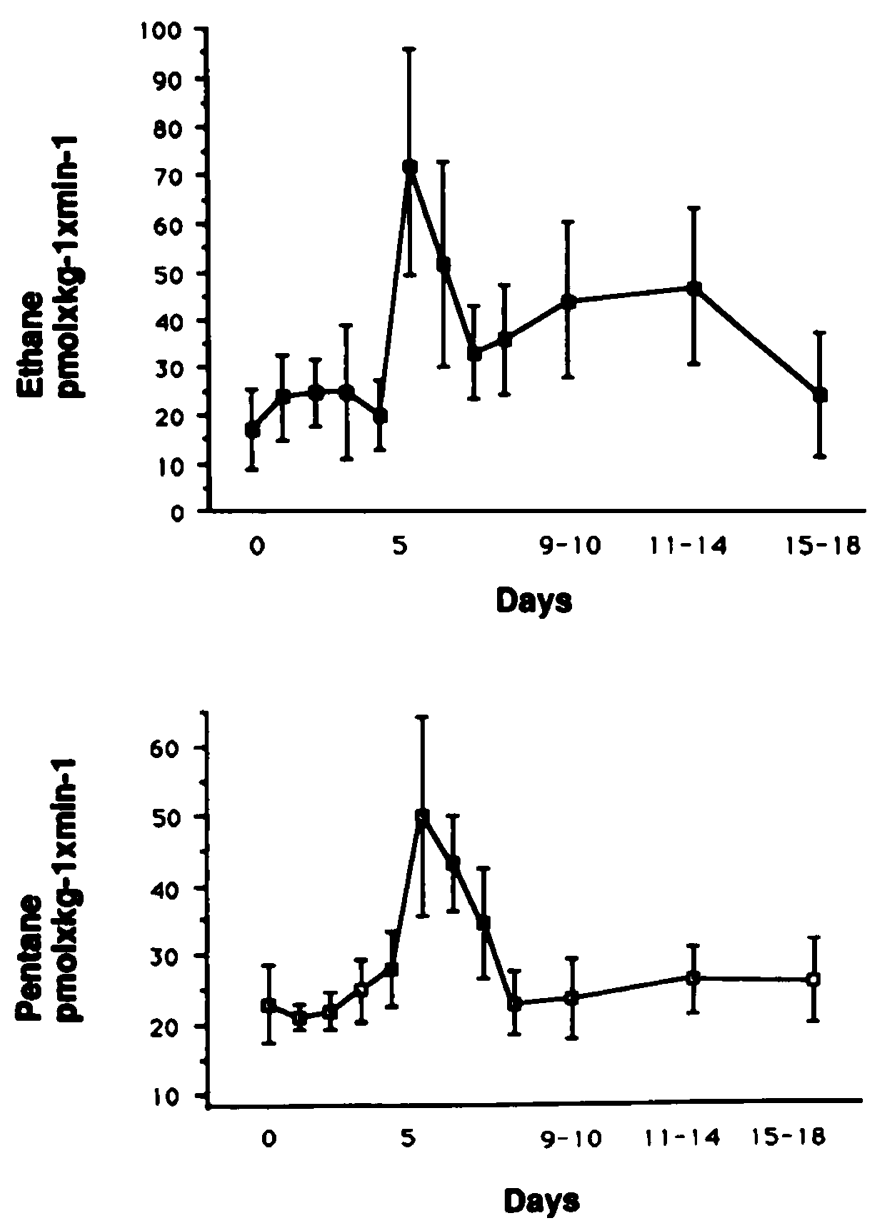

Figure 1. Expired ethane (upper panel) and pentane (lower panel) in 27 premature infants during the first $2 \mathrm{wk}$ of life. Values are given as the mean \pm SEM of 15 to 21 measurements/d on $d 1$ to 7 and of 7 to 19 measurements/d on $\mathrm{d} 7$ to 18 .

tation. However, both the actual fraction of inspiratory oxygen requirement and the cumulative fraction of inspiratory oxygen requirement had a nonsignificant association with the ethane and pentane peaks $(p \geq 0.10)$.

High excretion of alkanes, i.e. maximum excretion exceeding $40 \mathrm{pmol} \times \mathrm{kg}^{-1} \times \mathrm{min}^{-1}$, was associated with BPD or neonatal death (ethane: OR, 6.5 ; $\mathrm{CI}, 1.1$ to 38.5 ; $p=0.03$; pentane: $\mathrm{OR}, 5.6$; $\mathrm{CI}, 1.1$ to $29.3 ; p=0.04$ ). BPD developed in nine patients according to the criteria of Bancalari and Gerhardt (16). Seven died (between 7 and $28 \mathrm{~d}$ ). No higher odds of IVH were observed among the preterm infants with high alkane excretion. IVH was found in 12 patients, of whom five had grade I (detected on $d$ 1-5) and seven had grades II-IV (detected on d 3-13).

Thirteen patients underwent treatment with indomethacin for PDA during the study period. High alkane excretion was not associated with the persistence of ductus. Two patients had stage 3 ROP. In one of these two infants, ethane was 19.6 and pentane was $65.4 \mathrm{pmol} \times$ $\mathrm{kg}^{-1} \times \mathrm{min}^{-1}$, and in the other infant, ethane was 200.5 and pentane was $31.6 \mathrm{pmol} \times \mathrm{kg}^{-1} \times \mathrm{min}^{-1}$.

Carbon dioxide remained stable in expired samples $\left[3.5 \pm 1.7(\mathrm{SD}) \mathrm{mL} \times \mathrm{kg}^{-1} \times \mathrm{min}^{-1}\right]$, indicating good recovery in different specimens.

\section{DISCUSSION}

The present data show a significant correlation between immaturity and postnatal free radical-mediated lipid peroxidation in preterm infants. A high level of lipid peroxidation in turn was associated with high neonatal mortality and increased incidence of BPD.

To some extent, free radical-mediated lipid peroxidation seems to be part of the normal metabolism (11). In 19 healthy term newborns, ethane and pentane excretion $\left(6.2 \pm 1.6 \mathrm{pmol} \times \mathrm{kg}^{-1} \times \mathrm{min}^{-1}\right.$ and $7.4 \pm 1.7 \mathrm{pmol} \times$ $\mathrm{kg}^{-1} \times \min ^{-1}$, respectively) remained low and remarkably stable during the 1st wk of life (unpublished data). However, in situations with an excess of free radicals, the lipid peroxidation cascade increases and becomes autocatalytic, resulting in pertubation of the membrane function and eventual cell death $(12,14,18)$. In premature infants, tissue damage caused by free radicals has been suggested as important in the development of several chronic complications, such as ROP, BPD, and IVH $(8-10)$. The present findings support a role for free radicals in the pathogenesis of chronic sequelae of the preterm infant.

Several explanations exist for high free radical activity in the preterm infants. The deleterious effects of hyperoxia and its association with increased production of free oxygen radicals is well known $(6,10)$. However, in the present patients both the birth weight and the length of gestation showed a significant negative association with level of lipid peroxidation, which hyperoxia failed to

Table 2. Factors associated with maximum alkane expiration: a multiple regression analysis

\begin{tabular}{|c|c|c|c|c|}
\hline Dependent variable & Independent variable & Regression coefficient & SEM & $p$ value \\
\hline \multirow[t]{5}{*}{ Log ethane $\left(\mathrm{pmol} \times \mathrm{kg}^{-1} \times \min ^{-1}\right)$} & Gestation at birth & -0.090 & 0.033 & 0.015 \\
\hline & Actual inspiratory $\mathrm{O}_{2}$ & 0.004 & 0.003 & 0.20 \\
\hline & Relative birth weight* & 0.01 & 0.06 & 0.82 \\
\hline & Sex $($ female $=1 ;$ male $=2)$ & 0.23 & 0.15 & 0.15 \\
\hline & & Constant term $=3.57$ & & \\
\hline \multirow{5}{*}{ Log pentane $\left(\right.$ pmol $\left.\times \mathrm{kg}^{-1} \times \min ^{-1}\right)$} & Gestation at birth & -0.048 & 0.017 & 0.013 \\
\hline & Actual inspiratory $\mathrm{O}_{2}$ & 0.0020 & 0.0019 & 0.32 \\
\hline & Relative birth weight* & -0.044 & 0.034 & 0.21 \\
\hline & Sex $($ female $=1 ;$ male $=2)$ & -0.026 & 0.084 & 0.76 \\
\hline & & Constant term $=2.95$ & & \\
\hline
\end{tabular}

\footnotetext{
* (Mean birth weight of infant - mean birth weight for infant's gestational age)/SD of mean birth weight at this gestational age).
} 
show. This finding differed from earlier report, where the oxygen requirement during the alkane peak correlated with alkane excretion (10). One reason for this discrepancy might be the larger number and wider range in the length of gestation of patients in the present study. Infants at a lower gestational age and with more severe conditions were included, which might also explain the overall higher content of alkanes excreted.

In the premature infants, a steep increase in lipid peroxidation took place at the end of the 1st wk of life. This pattern of free radical activity in preterm infants is in accordance with previous findings (10). The reason for the peak activity during this period is enigmatic, however. When ethane and pentane are measured, potential contamination (e.g. from intestinal bacterial flora) has to be excluded (19). However, in our patients this possibility is unlikely because of the broad-spectrum antibiotics given to the premature infants and because of the remarkably stable levels of ethane and pentane in term infants receiving breast milk and therefore establishing an intestinal bacterial flora during the 1 st wk of life (20).

An event of potential importance for the increase in lipid peroxidation is the recruitment of phagocytizing cells and increased inflammation in the lungs observed in preterm infants with respiratory distress syndrome at the end of the 1st postnatal wk (21). During this period, decreased concentrations of the antioxidant lactoferrin are also found in patients who later have BPD (22). In premature infants, levels of vitamin $E(23)$ and of antioxidant scavengers such as transferrin and ceruloplasmin are low $(24,25)$. The protective antioxidant enzymes have a low activity and a poor inducibility in hyperoxia $(3,4)$. Therefore, toward the end of the 1 st wk of life, the antioxidant defense system of the premature infant may be overwhelmed by free radicals generated by hyperoxia, inflammatory responses, or, possibly, reperfusion events $(7,26)$.

Ethane and pentane are formed in free radicalmediated lipid peroxidation from $\omega-3$ and $\omega-6$ polyunsaturated fatty acids, respectively $(13,14)$. Although analogous in principle, the two alkanes show some differences. First, in in vitro lipid peroxidation the stoichimetric yield of ethane from its parent compounds is somewhat higher than that of pentane (13). Second, tissue oxygen tension may influence the formation of the alkanes $(27,28)$. Third, the alkanes may be metabolized differently (29). Finally, with the use of the present method the quantitation of pentane is more accurate than that of ethane (14). These factors may account for the differences found here between ethane and pentane. However, concerning the rapid increase in lipid peroxidation occurring on the 5 th postnatal $d$, and probably reflecting free radicalmediated tissue damage, the patterns of the two alkanes show striking similarity.

After its maximum level toward the end of the 1st wk, lipid peroxidation gradually returns to a level close to that measured during the 1 st postnatal $\mathrm{d}$. The latter phenomenon is in accordance with previous data by Pitkänen et al. (10) and seems to be a constant pattern of free radicalmediated effects in premature infants. It is not caused by artefacts, such as changes in the patient population (for instance, the death of moribund patients). One reason might be lack of substrate for lipid peroxidation, i.e. polyunsaturated fatty acids. However, this reason is improbable with regard to the lungs because the content of polyunsaturated fatty acids of tracheal aspirates of preterm infants remains unchanged during the 1 st wk of life despite changes in lipid peroxidation (30) (unpublished results). Another explanation is that the lipid peroxidation process is self-limiting. The reason for this limitation might be either decreased generation of free radicals, perhaps because of a lower degree of inflammation or hyperoxia, or adaptation of the antioxidant defense.

In the present patients, however, only high lipid peroxidation (alkane excretion exceeding $40 \mathrm{pmol} \times \mathrm{kg}^{-1} \times$ $\min ^{-1}$ ) correlated with complications. The level of lipid peroxidation after the 1st wk, potentially indicative of the capacity of the patient to limit the effects of free radicals, did not correlate with the clinical course.

In conclusion, immaturity in premature infants was the single most important denominator linked with free radical-mediated lipid peroxidation. In these patients a rapid increase in lipid peroxidation is seen on the 5 th $\mathrm{d}$ of life, and this high level correlates with a high risk of dying or with having BPD develop. Therapies for reduction of the effects of free radicals should be started before birth or immediately postnatally in premature infants to be effective.

Acknowledgments. The authors thank Maija Pohjavuori, M.D., Kari Raivio, M.D., and the personnel of the Neonatal Intensive Care Unit, Children's Hospital, for their kind cooperation. We are also grateful to Sinikka Tsupari for skillful technical assistance.

\section{REFERENCES}

1. Yam J, Frank L, Roberts RJ 1978 Oxygen toxicity: comparison of lung biochemical responses in neonatal and adult rats. Pediatr Res 12:115-119

2. Lindeman JHN, van Zoeren-Grobben D, Schrijver J, Speel AJ, Poorthuis BJHM, Berger HM 1989 The total free radical trapping ability of cord blood plasma in preterm and term babies. Pediatr Res 26:20-24

3. Frank L, Sosenko I 1991 Failure of premature rabbits to increase antioxidan enzymes during hyperoxic exposure: increased susceptibility to pulmonary oxygen toxicity compared with term rabbits. Pediatr Res 29:292-296

4. Sullivan JL, Newton RB 1988 Serum antioxidant activity in neonates. Arch Dis Child 63:748-757

5. Gutcher Gr, Raynor WJ, Farrell PM 1984 An evaluation of vitamin E status in premature infants. Am J Clin Nutr 40:1078-1089

6. Turrens JF, Freeman BA, Crapo JD 1982 Hyperoxia increases $\mathrm{H}_{2} \mathrm{O}_{2}$ release by lung mitochondria and microsomes. Arch Biochem Biophys 217:411-421

7. Saugstad OD 1990 Oxygen toxicity in the neonatal period. Acta Paediatr Scand 79:881-892

8. Johnson L, Schaffer D, Boggs TR 1974 The premature infant, vitamin E deficiency and retrolental fibroplasia. Am J Clin Nutr 27:1158-1173

9. DeLemos RA, Coalson JJ, Gerstmann DR, Kuehl TJ, Null DM 1987 Oxygen toxicity in the premature baboon with hyaline membrane disease. Am Rev Respir Dis 136:677-682

10. Pitkänen $O M$, Hallman $M$, Andersson S 1990 Correlation of free oxygen radical-induced lipid peroxidation with outcome in very low birth weight infants. J Pediatr 116:760-764

11. Dormandy TL 1988 In praise of peroxidation. Lancet 2:1126-1128

12. Hochstein P, Jain SK 1981 Association of lipid peroxidation and polymerization of membrane proteins with eryhrocyte aging. Fed Proc 40:183-188

13. Dumelin EE, Tappel AIL 1977 Hydrocarbon gases produced during in vitro peroxidation of polyunsaturated fatty acids and decomposition of preformed hydroperoxides. Lipids 12:894-900 
14. Pitkänen OM, Hallman M, Andersson SM 1989 Determination of ethane and pentane in free oxygen radical induced lipid peroxidation. Lipids 24:157-159

15. Papile LA, Burnstein J, Burnstein R, Koffler H 1978 Incidence and evolution of subependymal and intraventricular hemorrhage: a study of infants with birth weight less than $1500 \mathrm{~g}$. J Pediatr 192:529-534

16. Bancalari E, Gerhardt 1986 Bronchopulmonary dysplasia. Pediatr Clin North Am 33:1-23

17. International Committee for the Classification of the Late Stages of Retinopathy of Prematurity 1988 An international classification of retinopathy of prematurity. Pediatrics $82: 37-43$

18. Pitkänen OM, Hallman M, Andersson S 1991 Generation of free radicals in lipid emulsion used in parenteral nutrition. Pediatr Res 29:56-59

19. Gelmont D, Stein RA, Mead JF 1981 The bacterial origin of breath pentane. Biochem Biophys Res Commun 102:932-936

20. Rotimi VO, Duerden BI 1981 The development of the bacterial flora in normal neonates. J Med Microbiol 14:51-62

21. Merritt TA, Cochrane CG, Holcomb K, Bohl B, Hallman M, Strayer D, Edwards III DK 1983 Elastase and $\alpha_{1}$-protinase inhibitor activity in tracheal aspirates during respiratory distress syndrome. J Clin Invest 72:656-666

22. Revinis ME, Kaliner MA 1992 Lactoferrin and lysozyme deficiency in airway secretions: association with the development of bronchopulmonary dysplasia. J Pediatr 121:262-270
23. Huijbers WAR, Schrijver J, Speek AJ, Deelstra BA, Okken A 1986 Persistent low plasma vitamin $E$ levels in premature infants surviving respiratory distress syndrome. Eur J Pediatr 145:170-171

24. Omene JA, Longe AC, Ihongbe JC, Glew RH, Holzman IR 1981 Decreased umbilical cord serum ceruloplasmin concentrations in infants with hyaline membrane disease. J Pediatr 99:136-138

25. Sullivan JL 1988 Iron, plasma antioxidants, and the "oxygen radical disease of prematurity." Am J Dis Child 142:1341-1344

26. Sibille Y, Reynolds HY 1990 Macrophages and polymorphonuclear neutrophils in lung defense and injury. Am Rev Respir Dis 141:471-501

27. Kostrucha J, Kappus $H 1986$ Inverse relationship of ethane or $n$-pentane and malondialdehyde formed during lipid peroxidation in rat liver microsomes with different oxygen concentration. Biochim Bhiophys Acta 879:120-125

28. Smith CV, Reilly MH 1989 Formation of pentane versus 1-pentanol in the ferrous sulfate initiated decomposition of 15-hydroperoxyeicosatetraenoic acid in hypoxic and hyperoxid conditions. Biochem Pharmacol 38:1362-1364

29. Wade CR, van Rij AM 1985 In vivo lipid peroxidation in man as measured by the respiratory excretion of ethane, pentane and other low molecular weight hydrocarbons. Anal Biochem 150:1-7

30. Kehrer JP, Autor AP 1977 Changes in the fatty acid composition of rat lung lipids during development and following age dependent lipid peroxidation. Lipids 12:596-603 